DOI: 10.20472/IAC.2018.044.040

\author{
SANDRA RIGOT \\ USPC, France
}

\title{
THE ENVIRONMENTAL REPORTING PRACTICES OF FRENCH PUBLIC COMPANIES: THE ACCOUNTING ISSUES FACED WITH CLIMATE RISKS
}

\begin{abstract}
:
The climate change and energy transition issues are a crucial stake for our societies. Indeed, while a large body of scientific work has shown the link between climate change acceleration and greenhouse gas emissions from productive processes, other studies have highlighted that profound changes in the climate would lead to increased risks for economic and financial activity and could have human impacts. The pursuit of high growth based on fossil fuels would lead economies to a disaster scenario. In the worst-case scenario, the IPCC estimates that the planet could heat up by 4.8 ${ }^{\circ} \mathrm{C}$ compared to the average temperature of the period 1986-2005 and the water rise by nearly a meter (threatening very populous coastal territories) not to mention the upsurge of extreme weather events. These gloomy forecasts highlight the urgency of action to try to contain global warming.

This transition to a low-carbon path requires taking on new challenges, including a substantial and sustainable GHG reduction through improved energy efficiency and decarbonation of production systems. This involves many risks related to producers' resilience, technological capabilities, the nature of policy instruments and their calibration to guide the transition. In the end, climate change involves two types of risks that can coexist: on the one hand, physical risks that result from damage directly caused by meteorological phenomena; on the other hand, transition risks resulting from adjustments made for a transition to a low-carbon economy. For companies in particular, they involve new risks but also opportunities that are not well taken into account in their reporting.

This article aims to draw up an inventory of the environmental reporting of CAC 40 companies over the period 2015-2017. The choice to study the French case is explained by its leadership in terms of transition. The idea is i) to understand the climate reporting practices of these companies, depending on the sectors and focusing on four areas that reflect how they can exploit, govern, develop their strategies and manage their risks ( in line with the Task Force on Climate-related Financial Disclosure (TCFD) analysis grid, an international initiative launched by Financial Stability Board in late 2015, (ii) to question the appropriateness of an intervention by the accounting standard-setter on the subject.
\end{abstract}

\section{Keywords:}

accounting, environmental reporting, climate risks 